\title{
Learning through dynamic tensions in a performance-based service-learning course
}

\author{
Melanie Bloom
}

\begin{abstract}
Tension is described as a "key quality in drama" (Kao \& O'Neill 1987: 28), but is it also an essential quality of drama as pedagogy? The present descriptive case study (Merriam 2009) explores the concept of tension and how and when it arose in a performance-based, service-learning course in Spanish. Student-produced documents as well as teacher-researcher observations were used to analyze the role of tension in the course. Results suggest that while the tensions students experienced evolved over the course of the semester, students remained engaged in the learning process.
\end{abstract}

\section{Introduction}

As Short and Burke (1991) remind us, learning is not entirely free from conflict, as the process of learning itself represents a tension between the known and the unknown. The concept of tension in learning has previously been examined in second language education (Bloom 2007; Huang 2006; Luke 2006; Schwarzer 2003; Spielmann \& Radnofsky 2001) as well as drama and drama education (Kao \& O'Neill 1998; Morgan \& Saxton 1987), but to this date no research has analyzed the role of tension in second language classrooms following a performance pedagogy. The present study explores the tensions that arose within the curriculum of a performance-based, service-learning Spanish course entitled "Latin American Theater through Performance." The study is framed within the broader literature of drama in second language education as well as both pedagogical and dramatic definitions of tension. The paper presents the curriculum development and design of the course, which involved several key stakeholders, including an elementary school, two local actors, and the advanced Spanish students enrolled in the course. In addition, it details the results of a qualitative study that explored students' reactions to the course, focusing on reported and observed tensions. 


\section{Drama in Second Language Education}

For over 50 years, language instructors have been incorporating role plays and other dramatic activities in their classes (Carkin 2007). However, scholars working in drama in second language education distinguish the use of dramatic activities from drama as pedagogy (Winston 2012). Drama as pedagogy can include a class based on a variety of dramatic techniques (Dodson 2000), an exploration of linguistic structures through drama (Even 2011; Schmenk 2015), process dramas (Stinson 2009; Stinson \& Freebody 2006) or full-scale dramatic productions (Essif 2002; Fonio 2012; Vázquez 2014). Although drama has been used to enhance teaching and learning in various educational contexts for decades (Carkin 2007), very few researchers in second language education have empirically examined the results of such a drama-based pedagogy. In fact, for the past several years, scholars have called for more empirical research with clearly reported methodology, on drama education and second language learning (see for example Carson 2012; Kao, Carkin \& Hsu 2011; Schewe 2013; Schmenk 2015; Stinson \& Winston 2011).

There are only a few empirical studies conducted internationally with identifiable and replicable research methodologies on drama in second language education. They focus on the role of drama in students' identity formation and linguistic self-confidence (Carson 2012; Shiozawa \& Donnery 2017), the comprehension of literary texts (Cheng \& Winston 2011; Koerner 2012), oral fluency (Dunn \& Stinson 2011; Podlozny 2000), questioning techniques (Janudom \& Wasnasomsithi 2009; Kao, Carkin \& Hsu 2011; Ryan-Scheutz \& Colangelo 2004) and foreign language anxiety (Piazzoli 2011; Saglamel \& Kayaoglu 2013). In their review of the literature on drama in second language learning Belliveau and Kim (2013: 6) note:

... despite a wide-spread pedagogical interest and scholarly conviction in the possibilities of educational drama in creating a more contextuallysituated, engaging, multi-modal, and empowering L2 learning experience, there is still little empirical evidence concerning what is actually taking place in L2 classrooms and how students perceive and react to their learning experiences when drama is introduced.

The present paper begins to fill this void in the literature by examining, via qualitative means, how students respond to an advanced university-level Spanish class based on a performative pedagogy. Like previous research in the area, it focuses on the impact of performance pedagogy, in this case large-scale production (Schewe 2013), on students' experiences in the language classroom. Specifically, this study explores the dynamic tensions that arose during the semester-long course and how these tensions affected the learning environment. 


\section{Tension Defined}

Because the present study is framed within the fields of second language education, drama, and drama education, the conceptualization of tension in each of these fields informed the data analysis. In the context of the second language classroom, the sometimes-conflicting expectations of teachers and students are often described as tensions. For example, Bloom (2007), Luke (2006), and Schwarzer (2003) explored the tensions that arose in their language classes when the instructor's role shifted from teacher-as-expert to teacher-as-facilitator. This change affects the responsibilities of the teachers, as rather than delivering teacher-centered lessons, instructors focus on structuring student-centered activities and responding to student issues and inquiries that arise spontaneously in class. This classroom structure often conflicts with students' previous language learning experiences creating tension. These types of tensions can help facilitate learner autonomy, as Luke (2006) notes, or they can lead to resistance to the pedagogical agenda of the teacher (Huang 2006). In the field of second language acquisition, the construct of tension was developed in contrast to foreign language anxiety (Horwitz, Horwitz \& Cope 1991), which is most frequently considered a debilitating anxiety. Spielmann and Radnofsky (2001: 259) describe tension as an "unstable phenomenon that may be generated by any situation or event and may be perceived differently by each individual experiencing it." Tensions in this definition are not inherently positive or negative, but rather exist on a continuum from euphoric (or positive in nature), to non-euphoric (not entirely positive while not detrimental), to non-dysphoric (not entirely detrimental while not positive), and, finally, to dysphoric (detrimental in nature).

Tension in drama and drama education has been defined slightly differently, but the definitions still refer to the mental or emotional engagement that a certain context inspires. Morgan and Saxton (1987: 3) define it as a "mental excitement" that "is fundamental to intellectual and emotional engagement, not only as a stimulus, but as the bonding agent that sustains involvement in the dramatic task." Whereas Kao \& O'Neill (1998: 28) describe tension within a process drama as "an essential structural principle in generating dramatic worlds." They go on to note that tensions arise due to different causes, that they can reveal themselves slowly or immediately, and that one tension often replaces another as dramatic action proceeds (ibid.). The various definitions presented here provided the framework for examining tensions in the present study. Specifically, Kao \& O'Neill's definition was used to frame the analysis of the data, examining the evolution of the tensions that arose during the creation of a large-scale dramatic production. These tensions inevitably formed the underlying structure of our class as they led to student anxiety and resistance, but also student engagement and bonding. Thus, the push and pull of the tensions students experienced may have helped them invest in the "dramatic task" (Morgan \& Saxton 1987: 3). 


\section{Curriculum Development and Research}

The Latin American Theater through Performance class was based on a partnership between university students, a fourth grade dual language program of a local elementary school, and a non-profit organization promoting arts education. The director of the non-profit organization donated the time of two professional actors, Neal and Marsha ${ }^{1}$, who would work with us on the course. Each collaborator participating in the class had different outcomes that needed to be met. The ESL and dual language coordinators' learning objective was to help their students learn to analyze the "theme" of a text. This connected the fourth graders' work in the course directly to one of the requirements of the state standardized test for which they were preparing. In addition to this academic objective, they wanted our university students, who came from similar linguistic and cultural backgrounds as their students, to serve as role models for the fourth graders, allowing them to see that a college education was in their future as well. The learning objectives for the university students were primarily to broaden their Spanish vocabulary as well as to develop new ways to critically and creatively interpret literary texts. As the course was a mixed-level undergraduate and graduate course, there were additional learning objectives for the graduate students. Because the graduate students were enrolled in a Master's program on language teaching, their objective was to develop engaging, performance-based lesson plans. In addition to lesson plan design, they also would serve as lead instructors during our visits with the elementary students.

\subsection{Participants}

Participants in this course were varied due to the three organizations involved in the development of the course. The participants included the dual language and ESL coordinators from the elementary school who served as our school liaisons and helped organize the logistics of our visits to the elementary school. In addition, we worked with 44 fourth graders enrolled in the program at the school. As mentioned previously, Neal and Marsha served as both our acting coaches and our directors once we proceeded to the rehearsal stage of the performance. Finally, and most importantly for this paper, 17 undergraduate and two graduate students participated in all aspects of the course. The student participants were all advanced students of Spanish, including four second language learners, 12 heritage language learners, and two native speakers (from Venezuela and Spain respectively). The two graduate students in the course served as stage managers for the production. Sixteen undergraduate students formed our cast, and one undergraduate student composed an original score for the production and performed it on his accordion. Eighteen of these students (16 undergraduates and two graduates) also agreed to participate in this research study on the curriculum.

${ }^{1}$ All names cited in the text are pseudonyms used to protect the privacy of the participants. 


\subsection{Course description}

The collaboration with the dual language program of the elementary school was pivotal to the course. Thus, the initial steps of course design began with the dual language and ESL coordinators for the program. During a spring meeting, I presented them with four potential plays that our students could teach and perform. The coordinators selected the text that they felt best reflected the concept of theme: Globito Manual (Reyes 2014). We also planned four visits with the fourth-grade students: the first would serve as an ice-breaker to introduce the students to each other, the second and third visits would explore the play's themes and include performance-based games, and the fourth visit would culminate with the university students' presentation of Globito Manual. Over the course of the 15-week semester, the university students prepared for these visits during two different units of instruction: The first six-week unit provided students an introduction to performance, and the second nine-week unit focused on the development of the large-scale dramatic production of Globito Manual.

During the first unit, Neal and Marsha visited on Mondays, leading the university students in performance-based games in order to build rapport and to develop comfort with physical performance. On these days, we generally worked bilingually as the actors had good Spanish comprehension but little productive ability. Examples of some of these initial games included walking in character, acting out single words, and re-enacting fairy tales. On Wednesdays, the students interpreted some aspect of a Latin American short story that they had read in preparation for class. We began the semester working on non-verbal interpretations, such as tableaux and tableaux in motion and, as the students became more accustomed to performing in front of their peers, moved into verbal interpretations, such as scripted alternate scenes and improvisation. During this time, we also prepared for our visits with the fourth-grade students.

Prior to our first visit with the elementary students, the school's dual language and ESL coordinators visited our class on campus. They delivered a presentation that outlined the district's dual language programming model as well as research on the program's outcomes. In addition, they described the linguistic and cultural background of the students generally enrolled in the program at their school. Finally, they outlined the learning objectives for our visits, providing our class with materials to help them introduce the concept of "theme" to the fourth graders. Using these materials, the students and I spent the week before each visit developing ideas for our lesson plans that would incorporate performance-based activities, the text Globito Manual, and the concept of theme. Based on these in-class discussions, the two graduate students developed detailed lesson plans that everyone would follow during the school visits.

In the second unit, the students, actor-directors and I focused on editing, casting, rehearsing, and performing Globito Manual. In addition, in order to actively include the fourth graders in the performance, we composed and choreographed original choral chants that they would perform at certain 
points during the final production. The second unit also included our visits with the elementary students in their school gymnasium as well as on our university's campus. These visits focused on two of the play's themes: the benefits of "hands," or the fruits of manual labor, and the literal and figurative metamorphosis of Globito, the main character. Teams of two to three university students led groups of about six elementary students through the activities that the graduate students had planned. Activities included ice-breaker performance games, small group discussions and acitivities based on the themes, and verbal and non-verbal performances in which the elementary students represented different characters from the play. During these visits, we also taught the fourth graders the chants and choreography that they would perform during the final production.

Throughout the semester, the university students completed various assignments to either prepare for a performance or a lesson or to reflect upon it. First, they read the short stories and the play assigned for class. Second, they completed weekly online reflections via the university's learning management system. These reflections centered on their responses to the readings, the in-class dramatizations, the interactions with the fourth graders, and the rehearsal process. Third, their preparation and participation in the group activities with the fourth graders were assessed via a performance-based rubric. Finally, the principal assessment of the course was the production as well as the processes leading up to the final performance (including the editing of the text and the rehearsals). Each of the three aspects of the production was assessed via an analyitical rubric.

\section{Research Study Design}

Due to my role as a highly invested participant-observer, the present study is framed as a teacher-research project (Hubbard \& Power 2003) that implemented a descriptive case study methodology (Merriam 2009). As this course was a new endeavor for all of the participants involved, the primary research question that I hoped to address was: What are students' reactions to a performance-based Spanish course? In order to answer this question, I implemented a variety of qualitative data collection techniques. These techniques included document analysis, through which I collected and analyzed student-created documents in the form of emails, reflections and other written work submitted for class. I also took teacher-researcher field notes after class in order to record any noteworthy interactions during the class period (ibid.). Fieldnotes also recorded some impromptu interactions outside of class. Finally, I conducted a whole class debriefing session, similar to a large focus group, after the final performance to ask students the following questions about their experience:

- How did the exercises we completed during the first half of the semester contribute to the process? What did you think about the use of short stories? 
- Was it important to edit the original text? Why or why not?

- In your opinion how did the rehearsals in class function? How could we improve the process?

- What did you learn from your participation in class this semester?

- How would you describe your experience to another student?

- Should this class be offered again in the future? Why or why not?

- If it is offered again, how should I revise it?

The data collected from these various sources were analyzed first using open coding (Merriam 2009), and secondarily using more analytic coding through which initial concepts were grouped into five broad categories and later refined to three. Through the data analysis process, my preliminary broad research question was refined to two specific questions. The present paper explores the questions: How and when do tensions arise in a performance-based Spanish course? What are the effects of tension on the learning environment?

\section{Students' Reactions: Dynamic Tension}

While the data revealed three thematic categories including group cohesion and student learning, the category that emerged as most frequent and impactful was that of tension in the classroom. Morgan and Saxton's (1987) definition of tension as both a stimulus and a "bonding agent" provides an excellent frame to discuss the tensions that arose within our class as students became performers and producers. Their journey from novice student performers to "experts" performing for a group of children was characterized by evolving tensions (Kao and O'Neill 1998) that bonded the group together, sustaining them in their dramatic work. This section explores the immediate tensions that arose at the outset of the course as well as the evolution of the tensions that formed the underlying structure of the course.

\subsection{Immediate Tensions}

Although certain amounts of tension existed throughout the semester, there were peaks at both the beginning and the end of the semester. These tensions arose first as students became accustomed to the pedagogy implemented in the class; and second, as the final performance loomed large in their minds. At the beginning of the term, students reported anxieties about the format of the course and about performing in front of their classmates as well as the elementary students. These immediate tensions were not entirely dysphoric, but rather revealed a continuum of tensions that ranged from dysphoric to euphoric.

Certain students revealed anxieties related specifically to performance and presentation. For example, Amelia stated: 


\begin{abstract}
After this first week of class, I am not sure how I feel. The first couple of days stressed me out. I wasn't sure what to expect. I am sure that it is obvious that I don't like to act, speak, etc. in front of the class. In fact, like I said in class, I studied vocal performance before studying Spanish. I had to give up that major due to my stage fright. I think that this class is bringing back to mind those stressful experiences from my past. Everyone has their own problems, and mine is not special, but it is important to note that it is more than just an aversion. That said, I hope that I can get over my anxieties and enjoy my time with my classmates because I liked the activities and the opportunity to learn different things about them. ${ }^{2}$
\end{abstract}

Although not all of the students shared Amelia's experience with this type of stage fright, three others expressed their aversion to performing and/or speaking in front of the class, something that caused them anxiety at the beginning of the term. In addition to performance anxiety, students also stated that they "felt silly" completing some of the performance-based games and activities during the first several weeks. For example, Sara noted, "It makes me feel bad because the truth is sometimes people look ridiculous doing these exercises, and it is then that the teasing starts in the group, and this is what I fear the most." Although there were no observed or reported instances of "teasing" in class, Sara was nervous that the performances would inspire this kind of behavior. Her comment was representative of those made by two other students about feeling uncomfortable completing activities in which they had to move and speak differently than they were used to.

Despite students expressing these tensions, which could be characterized as dysphoric to non-dysphoric, tensions that were more euphoric in nature were also noted at the beginning of the semester. Although some of the students enrolled in the course knew one another at the outset, for the most part, this group of students had not worked together previously. Because the students were not well acquainted, it was surprising how quickly the class identified as a "group" rather than as individuals. In the first week's reflection, eight students mentioned that their identification with others in the group was helpful in calming anxieties about performing and/or noted that the supportive environment helped them feel more comfortable. For example, one student commented, "I think the manner in which the games were played let us get to know more about everyone in class. We realized that we can work in a team since we have things in common and we share similar ideas." Similarly, Laura noted that, "no one was judging other people, and I feel more comfortable working with them [her classmates]."

The in-class performance activities required students to be in a vulnerable position. However, they not only got to know each other quickly, but they also developed trust in one another. For example, at the beginning of the semester, Carla noted, "In Spanish class, we have to act, leave our comfort zones and interact with our classmates in different ways." It could be that this "different way" of interacting with classmates (via performance) served as a euphoric tension that kept students both engaged in the class and allowed them to form 
a group or team mindset rather than a more individualistic one.

\subsection{Evolving Tensions}

While in the first part of the semester, students expressed anxiety about performance in general, once the play was cast (in week six of the course), the tensions that evolved demonstrated students' investment in the production. Students questioned directorial decisions, such as casting or blocking, doubted one another, and worried about costumes, make-up, and props. These tensions evolved as the final production began to take shape and had both dysphoric and euphoric effects on the students.

Following Essif's (2002: 120) strategies for collaborative regeneration of a dramatic text, two activities were conducted in class to allow students to reflect on the script itself as well as their particular characters. First, students met in small groups to suggest possible edits to the script to make it more accessible to our fourth-grade audience as well as to make it easier for students to memorize. Second, students were encouraged to reflect upon how they might reinvent their character through voice, movement, script edits, etc. in order to "personalize" their performance. These activities were implemented so that students could begin to take ownership of the play as well as their individual performances, but they caused unanticipated tensions as the students were more comfortable with interpreting what was "on the page." For example, Raquel stated "The classes this week stressed me out. Especially Monday's class. I felt really negative about looking for ways to develop our own version of Globito Manual." Likewise, Carmen mentioned that eliminating or editing lines would take away from the "charm" of the play. Similarly, students were uncomfortable with the task of "reinventing" their character to include some aspect of themselves. Emma stated in her reflection, "I think that for the group of us that make up Globito, it was difficult to imagine how we are going to invent the character on stage. I think it is really different than what we are used to doing." Four other students also stated that they did not know how to reinvent their character and/or that the character should be interpreted as written. These comments perhaps demonstrate a tension between the creative interpretation that the students were asked to do in this course and the more literal interpretations that they were accustomed to completing in other language and literature courses. In this case, the tension resulting from these activities had a detrimental effect on class participation. Three out of the five groups of students working on these edits and interpretations completed no productive work during class, and the negative energy generated in class that week carried over to the following week, as students came to class ill-prepared to rehearse.

Students' literal interpretation of the text also created tensions between their expectations of the staging of the performance and the directors' and instructor's perceptions. As we were producing the play on essentially no budget, all costumes, props, and make-up were either items that we collectively already possessed or that could be purchased by the instructor. David summed 
up this tension well by stating:

As for me, when I think about the various things that we can do, there is a certain conflict. I am referring to the fact that we don't even have the most basic resources, and all of us want to present Globito Manual in the best way possible. Yes, it's true that children have big imaginations; and maybe, people like me, we think too much about the details.

While four other students noted the limited budget and the need for simplicity, nine students came up with elaborate ideas for scenery, costumes, and props that required a substantial investment in time and money. These complex ideas sometimes reflected the students' literal interpretation of the play. For example, two students wanted to create cardboard cut-outs of the characters that they were to interpret. Other ideas were based on the students' desire to create an environment that would hold the fourth graders' attention. Regardless, both types of ideas reflect the students' desire to draw the audience's attention to backdrops, props and elaborate costumes, in order to minimize the focus on their own voices and movements. Laura noted something similar in her tenth reflection when she stated:

After this week, I realized that we are paying more attention to things like costumes and music. These things are important but we need to focus on memorizing the lines of the play. I know the reason why I was paying more attention to the other aspects is because it takes away from the pressure of having to act.

As we moved into the rehearsal stage of the semester, the students' anxieties about the production increased causing negative tensions to arise as students began to comment on one another's lack of preparedness. However, more euphoric tensions were also observed as students put renewed emphasis on both their own performances and the production itself. Leading up to the final performance, students made 28 comments in their reflections about the importance of class/rehearsal attendance, the memorization of lines, voice projection, and "having fun" with their characters. These comments were often self-critical, but also served as subtle ways of encouraging their classmates who needed to work on these aspects of their performance. For example, Nick stated:

After Wednesday, I completely agree with Neal when he told us that the sooner we memorize our lines, the better because when we were practicing the scenes, I felt like I wasn't capable of acting the way I wanted to because I had the script in my hand. I felt like I could only read it and not convey enough emotion.

Nick was not the only student to mention the importance of being off-script. Several other students mentioned that lines needed to be memorized so that student actors could pay more attention to other aspects of their performance. For example, Amelia noted the relationship between knowing lines well and voice projection stating: 
When some people aren't sure of their lines, they speak quietly and the scene loses energy. When they get to a part in which they do know the lines, it seems like their minds are still worried about the past and it is hard to recover the energy. Also, when they do speak up, the problem areas are obvious and we can correct them.

Finally, in relation to adding more "personality" to their performances, Laura stated, "About our roles, we need to add more personality. Like Marsha said, what we are portraying should be fun." Thus, these types of comments served as a critique, but also perhaps a form of encouragement to focus or re-focus students' efforts. As Amelia reminded her classmates, "The most important thing is the project (that is, the children) and they don't want to see uninterested university students."

Tensions that arose from students' anxieties about their individual performance or the group production were important to the learning process as they led students to discover more about themselves and to learn more about theatrical production and performance for children. As students' performances evolved, some began to apply the techniques they learned earlier in the semester as well as the feedback they received during the preliminary rehearsals. The improvements in their performance did not go unnoticed by their fellow students, and they began to serve as model actors. Thus, for some students, the disconnect between their own performance and that of their peers created a euphoric tension, which helped students re-invest in the production. For example, during a feedback session after one of the rehearsals, Marsha enouraged students to incorporate in their performances the features of the inanimate objects they were representing. In response Laura commented,

I think that David did a good job with this. The way he speaks and walks, I can connect his actions to a tree. Carlos as well, in the way he walks in the opening scenes. I like it because it is believable that he is a balloon. Maybe he feels a little uncomfortable or silly but he is dedicated to his character just like David.

This demonstrates how Laura was able to learn from her fellow actors and how she saw the concepts discussed in class applied to their performances. Likewise, Erica commented on the same topic, and her admiration of the way David, Amelia, and Sara gave unique voices to their characters through their performances. Another student mentioned voice projection specifically, noting how Nick's voice commanded the audience's attention while he was on-stage. Similarly, Emma admired the way that both Carla and David used the entire stage during their performances, rather than staying frozen in one spot as others did. She observed, "This week I have learned a lot of things, not just by doing the activities but also absorbing what others do." These comments taken together indicate the euphoric tension that came from students' observations of one another's performances and how they actively learned from their peers. Raquel perhaps summarized the results of these tensions best in her last reflection noting: 
At least I feel like I learned a lot this semester, especially about myself. Each and every rehearsal, every change in the play, each reflection they all feel in this moment special and important. And seeing the faces of my classmates, proud of themselves, was the biggest reward for all the hard work this semester.

Thus, despite both the immediate and evolving tensions students experienced throughout the semester, they stayed engaged in the process and the production and viewed it as worth the effort.

\section{Conclusion}

The tensions experienced during the development and realization of this performance-based, service-learning course were not always comfortable, but they provided the underlying structure for learning to occur. Going through phases of uncertainty, debate, and critique, students were challenged to solve problems in new ways. This process also allowed the students to express themselves in ways that many of them had never done before, both in Spanish and through movement. The fact that all students participated in the final production with enthusiasm, provides additional evidence of their engagement in the process. In the end, both in their final reflections and in our class debriefing session, every student involved in the course reported having had a positive experience, and almost all noted that they felt a sense of accomplishment at the end of the semester.

The results of this study suggest that the process of learning through performance can and should be filled with tension, because tension ultimately leads to learning. Yasmin perhaps summarized this best when she reflected on her experience at the end of the semester; she noted, "We can learn a lot from this experience, from how to work in a team, to trusting others, to overcoming our fears and anxieties and all of this in a fun way for the entertainment of a group of children."

Because these shared perspectives were unique to this particular group of students, educators working with students in other contexts may experience their own unique set of tensions. For example, students at lower levels of language proficiency may experience tensions related to foreign language anxiety or linguistic self-confidence that my students did not. The challenges and rewards that arose from working with and for the benefit of children also sustained this particular group of students in the dramatic task. Students working in other contexts might not feel the tension that stemmed from the desire to not only entertain the audience, but also to not disappoint the group of children that the students had come to know. Thus, I would encourage educators working in different contexts to examine how tension might serve as an underlying structure of their dramatic work. 


\section{Bibliography}

Belliveau, George \& Kim, Won (2013): Drama in L2 Learning: A Research Synthesis. In: Scenario VII/2, 6-26

Bloom, Melanie (2007): Tensions in a Non-traditional Spanish Classroom. In: Language Teaching Research 11/1, 85-102

Carkin, Gary (2007): Teaching English through Drama: The State of the Art. https://tesoldrama.files.wordpress . com [last accessed June 16, 2017]

Carson, Lorna (2012): The Role of Drama in Task-based Learning: Agency, Identity and Autonomy. In: Scenario VI/2, 46-59

Cheng, Astrid Yi-Mei \& Winston, Joe (2011): Shakespeare as a Second Language: Playfulness, Power and Pedagogy in the ESL Classroom. In: Research in Drama Education: The Journal of Applied Theatre and Performance 16/4, 541-556

Dodson, Sarah L. (2000): FAQs: Learning Languages through Drama. In: Texas Papers in Foreign Language Education 5/1, 129-141

Dunn, Julie \& Stinson, Madonna (2011): Not without the Art!! The Importance of Teacher Artistry when Applying Drama as a Pedagogy for Additional Language Learning. In: Research in Drama Education: The Journal of Applied Theatre and Performance 16/4, 617-633

Essif, Les (2002): (Re-)Creating the Critique: In(tro)ducing the Semiotics of Theatre in the Foreign-language Performance Project. In: Theatre Topics $12 / 2,119-142$

Even, Susanne (2011): Drama Grammar: Towards a Performative Postmethod Pedagogy. In: Language Learning Journal 39/3, 299-312

Fonio, Filippo (2012): Stuffed Pants! Staging Full-scale Comic Plays with Students of Italian as a Foreign Language. In: Scenario VI/2, 17-26

Horwitz, Elaine K., Horwitz, Michael B. \& Cope, Joann (1991): Foreign Language Classroom Anxiety. In: Horwitz, Elaine K. \& Young, Dolly A. (eds.): Foreign Language Anxiety: From Theory to Research and Classroom Implications. Upper Saddle River, NJ: Prentice Hall, 27-36

Huang, Jing (2006): Learner Resistance in Metacognition Training? An Exploration of Mismatches between Learner and Teacher Agendas. In: Language Teaching Research 10/1, 95-117

Hubbard, Ruth Shagoury \& Power, Brenda Miller (2003): The Art of Classroom Inquiry: A Handbook for Teacher-Researchers. Portsmouth, NH: Heinemann

Janudom, Ratchadaporn \& Wasnasomsithi, Punchalee (2009): Drama and Questioning Techniques: Powerful Tools for the Enhancement of Students' Speaking Abilities and Positive Attitudes towards EFL Learning. In: ESP World 26/5, n.p. http://www. esp-world.info. [last accessed January 30, 2018]

Kao, Shin Mei, Carkin, Gary \& Hsu, Liang-Fong (2011): Questioning Techniques for Promoting Language Learning with Students of Limited L2 
Oral Proficiency in a Drama-oriented Language Classroom. In: Research in Drama Education: The Journal of Applied Theatre and Performance 16/4, 489-515

Kao, Shin Mei \& O'Neill, Cecily (1998): Words into Worlds: Learning a Second Language Through Process Drama. Westport, CT: Greenwood

Koerner, Morgan (2012): German Literature and Culture Under Revue: Learner Autonomy and Creativity through the Theme-based Theater Practicum. In: Die Unterrichtspraxis 45/1, 28-39

Luke, Christopher L. (2006): Fostering Learner Autonomy in a Technology-Enhanced, Inquiry-Based Foreign Language Classroom. In: Foreign Language Annals 39/1, 71-86

Merriam, Sharan B. (2009): Qualitative Research: A Guide to Design and Implementation. San Fransisco, CA: Jossey-Bass

Morgan, Norah \& Saxton, Juliana (1987): Teaching Drama: A Mind of Many Wonders. Cheltenham, UK: Nelston Thornes

Piazzoli, Erika (2011): Process Drama: The Use of Affective Space to Reduce Language Anxiety in the Additional Language Learning Classroom. In: Research in Drama Education: The Journal of Applied Theatre and Performance 16/4, 557-573

Podlozny, Ann (2000): Strengthening Verbal Skills through the Use of Classroom Drama: A Clear Link. In: Journal of Aesthetic Education 34/3, 239-275

Reyes, Carlos José (2014): Globito Manual. Bogata, Colombia: Panamericana Editorial

Ryan-Scheutz, Colleen \& Colangelo, Laura M. (2004): Full-scale Theater Production and Foreign Language Learning. In: Foreign Language Annals 37/3, 374-385

Saglamel, Hasan \& Kayaoglu, Mustafa N. (2013): Creative Drama: A Possible Way to Alleviate Foreign Language Anxiety. In: RELC Journal 44/3, 377-394

Schwarzer, David (2003): A Qualitative Assessment of a Foreign Whole Language Class. In: Foreign Language Annals 36/1, 77-85

Schewe, Manfred (2013): Taking Stock and Looking Ahead: Drama Pedagogy as a Gateway to a Performative Teaching and Learning Culture. In: Scenario $\mathrm{VII} / 1,5-28$

Schmenk, Barbara (2015): Drama in the Classroom: Post-Holistic Considerations. In Parkes, Lisa \& Ryan, Colleen M. (eds.): Integrating the Arts: Creative Thinking about FL Curricula and Language Program Direction. Boston, MA: Cengage, 91-108

Shiozawa, Yasuko \& Donnery, Eucharia (2017): Overcoming Shyness: Promoting Leadership and Communication through English Drama Camp in Japan. In: Scenario XI/2, 15-30

Short, Kathy G. \& Burke, Carolyn (1991): Creating Curriculum: Teachers and Students as a Community of Learners. Portsmouth, NH: Heinemann 
Spielmann, Guy \& Radnofsky, Mary L. (2001): Learning Language Under Tension: New Directions from a Qualitative Study. In: The Modern Language Journal 85/2, 259-278

Stinson, Madonna (2009): Drama is Like Reversing Everything: Intervention Research as Teacher Professional Development. In: Research in Drama Education: The Journal of Applied Theatre and Performance 14/2, 225-243

Stinson, Madonna \& Freebody, Kelly (2006): The DOL Project: The Contributions of Process Drama to Improved Results in English Oral Communication. In: Youth Theatre Journal 20/1, 27-41

Stinson, Madonna \& Winston, Joe (2011): Drama Education and Second Language Learning: A Growing Field of Practice and Research. In: Research in Drama Education: The Journal of Applied Theatre and Performance 16/4, 479-488

Vázquez, Karina (2014): Speaking Out Loud: Deconstructing Shame and Fear through Theater in a Community-based Service-learning Project. In: Journal on Excellence in College Teaching 25/1, 113-137

Winston, Joe (2012): Introduction: Second and Additional Language Learning through Drama. In Winston, Joe (ed.): Second Language Learning through Drama: Practical Techniques and Applications. London, UK: Routledge, 1-5 